\title{
Facile hydrothermal preparation of titanium dioxide decorated reduced graphene oxide nanocomposite
}

This article was published in the following Dove Press journal:

International Journal of Nanomedicine

4 July 2012

Number of times this article has been viewed

\author{
Betty Yea Sze Chang' \\ Nay Ming Huang' \\ Mohd Nor An'amt ${ }^{2}$ \\ Abdul Rahman Marlinda' \\ Yusoff Norazriena' \\ Muhamad Rasat Muhamad ${ }^{3}$ \\ Ian Harrison ${ }^{4}$ \\ Hong Ngee Lim $^{5}$ \\ Chin Hua Chia ${ }^{6}$ \\ 'Low Dimensional Materials Research \\ Center, Physics Department, \\ University of Malaya, Kuala Lumpur; \\ ${ }^{2}$ Faculty of Agro Industry and Natural \\ Resources (FASA), Universiti Malaysia \\ Kelantan, Kota Bharu, Kelantan; ${ }^{3}$ The \\ Chancellery Building, Multimedia \\ University, Persiaran Multimedia, \\ Cyberjaya, Selangor; ${ }^{4}$ School of \\ Chemical and Environmental \\ Engineering, The University of \\ Nottingham Malaysia Campus, \\ Semenyih, Selangor; ${ }^{5}$ Department \\ of Chemistry, Faculty of Science, \\ Universiti Putra Malaysia, Serdang, \\ Selangor; ${ }^{6}$ School of Applied Physics, \\ Universiti Kebangsaan Malaysia, \\ Bangi, Selangor, Malaysia
}

Correspondence: NM Huang Low Dimensional Materials Research Center, Physics Department, University of Malaya, 50603 Kuala Lumpur, Malaysia Tel +60 379674295

Fax +60 $379674 \mid 46$

Email huangnayming@gmail.com
Abstract: A simple single-stage approach, based on the hydrothermal technique, has been introduced to synthesize reduced graphene oxide/titanium dioxide nanocomposites. The titanium dioxide nanoparticles are formed at the same time as the graphene oxide is reduced to graphene. The triethanolamine used in the process has two roles. It acts as a reducing agent for the graphene oxide as well as a capping agent, allowing the formation of titanium dioxide nanoparticles with a narrow size distribution $(\sim 20 \mathrm{~nm})$. Transmission electron micrographs show that the nanoparticles are uniformly distributed on the reduced graphene oxide nanosheet. Thermogravimetric analysis shows the nanocomposites have an enhanced thermal stability over the original components. The potential applications for this technology were demonstrated by the use of a reduced graphene oxide/titanium dioxide nanocomposite-modified glassy carbon electrode, which enhanced the electrochemical performance compared to a conventional glassy carbon electrode when interacting with mercury(II) ions in potassium chloride electrolyte.

Keywords: graphene oxide, titanium oxide, hydrothermal, nanocomposite

\section{Introduction}

Graphene is a monocrystalline graphitic film a few atoms thick and is stable under ambient conditions. The physical dimension of the film's thickness ensures the electronic structure of the material is two-dimensional. Moreover, there is a small overlap between the valence and conduction bands, and graphene exhibits semimetal behavior. With the addition of a gate electrode, electron and hole concentrations in the channel can be as high as $10^{13} \mathrm{~cm}^{-3}$ with mobility at room temperature in the order of $10,000 \mathrm{~cm}^{2} \mathrm{~V}^{-1} \mathrm{~s}^{-1}$. These results make graphene an ideal candidate for the next generation of electronic devices. ${ }^{1}$ In addition, graphene has extremely good mechanical and thermal properties and thus has potential application over a wide variety of uses such as composite materials, fuel cells, batteries, chemical detectors, and solar cells. ${ }^{2-11}$ Moreover, the integration of graphene with inorganic nanoparticles allows the properties of the nanocomposite to be engineered for specific applications, which is rapidly becoming a research trend as the nanocomposites are able to exhibit properties that are not found in the individual components. ${ }^{6,12-18}$

Nanocrystalline titanium dioxide $\left(\mathrm{TiO}_{2}\right)$ is a promising candidate for solar energy conversion applications such as photocatalysis, photochromism, and photovoltaics because of its unique optical and electrical properties. ${ }^{19}$ It is widely used in applications such as hydrogen production, ${ }^{20,21}$ gas sensors, ${ }^{22,23}$ photocatalytic activities, ${ }^{24,25}$ and dye-sensitized solar cells ${ }^{26,27}$ because of its relative high efficiency and high stability. 
The microbiocidal effects of $\mathrm{TiO}_{2}$ photocatalytic reactions ${ }^{28}$ clearly have pharmacological applications and $\mathrm{TiO}_{2}$ photocatalytic reactions have been used to kill a wide spectrum of organisms including bacteria, ${ }^{29}$ viruses, ${ }^{30}$ fungi, ${ }^{31}$ cancer cells, ${ }^{32}$ and algal toxins. ${ }^{33}$ In addition, antibacterial activity against four common human pathogens, namely Escherichia coli, Pseudomonas aeruginosa, Klebsiella pneumoniae, and Staphylococcus aureus, has also been demonstrated. ${ }^{34}$ In addition, the oxidizing power of $\mathrm{TiO}_{2}$ when under irradiation of ultraviolet (UV) light in either water or an oxygen-rich environment means that irradiated $\mathrm{TiO}_{2}$ can be used in waste processing because of its ability to decompose and/or oxidize most organic and/or inorganic compounds. ${ }^{36,37}$ Interestingly, its high chemical stability and nontoxicity also makes $\mathrm{TiO}_{2}$ biocompatible, and it is used in many cosmetic products and as an alternative material for improving antimicrobial properties. For example, $\mathrm{TiO}_{2}$ nanoparticles have been added to dental acrylic resins to improve the color. ${ }^{35}$

The challenge when developing convenient and effective processing technologies for the fabrication of graphene nanocomposites is the prevention of the restacking and/or agglomeration of the graphene sheets caused by the changes in the Van der Waals interactions due to the presence of metal oxide particles like $\mathrm{TiO}_{2} \cdot{ }^{38,39}$ Recently, graphene $/ \mathrm{TiO}_{2}$ nanocomposites have been synthesized using technologies such as atomic layer deposition ${ }^{40}$ and electron beam irradiation. ${ }^{41}$ Although successful, these methods are probably not commercially viable since the processes require a sixstep sequence with heat treatment at various temperatures ${ }^{40}$ or pretreated graphene ${ }^{41}$ as a raw material. Furthermore, other reported techniques that use hazardous chemicals, such as hydrazine hydrate, create dangerous by-products such as hydrogen fluoride. ${ }^{42}$ Other reported problems in the formation of graphene nanocomposites include the lack of discrete nanocrystalline $\mathrm{TiO}_{2}$ particles before calcination ${ }^{43}$ and agglomeration of the $\mathrm{TiO}_{2}$ particles. ${ }^{44,45}$

In this paper, a one-step hydrothermal route for the preparation of graphene $/ \mathrm{TiO}_{2}$ nanocomposites using graphene oxide (GO) and titanium isopropoxide as starting materials with the addition of triethanolamine (TEA) is reported. The hydrothermal technique was chosen because it is a "soft solution chemical processing" technique, which provides an easier way to control particle size, particle morphology, microstructures, phase composition, and surface chemical properties with adjustments in experimental parameters such as temperature, pressure, duration of process, and $\mathrm{pH}$ value of solution. ${ }^{46-49}$ This one-step hydrothermal method is convenient and safe, and with the addition of TEA to the solution, the process provides a route to manufacture graphene $/ \mathrm{TiO}_{2}$ nanocomposites where the $\mathrm{TiO}_{2}$ nanoparticles are discrete with no agglomeration of the particles. This is not the first time a single-step hydrothermal technique has been reported; however, there are significant differences between the process reported in this paper and those already published. Shen et al reported an "intrinsically pure process," which utilized only water and glucose.$^{50}$ However, their sample prior to hydrothermal treatment contained ammonium chloride, ethanol, glucose, and ammonium hydroxide. ${ }^{50}$ In the method reported here, only TEA and ethanol were added. Other reported one-step hydrothermal processing studies used ultrasonication to obtain a well-dispersed suspension of GO and $\mathrm{TiO}_{2}$. This step was omitted in the current work.

The objective of this work was to study the influence of the hydrothermal temperature on the crystallinity, size distribution, thermal stability, and electrochemical performance of reduced $\mathrm{GO}(\mathrm{RGO}) / \mathrm{TiO}_{2}$ nanocomposites. To the best of the authors' knowledge, the effect of TEA and reaction temperature on the formation of $\mathrm{RGO} / \mathrm{TiO}_{2}$ nanocomposites has not been previously reported.

\section{Material and methods Materials}

Graphite 3061 and titanium isopropoxide (99\%) were purchased from Asbury Graphite Mills Inc (Asbury, NJ) and Acros Organics (Geel, Belgium), respectively; TEA and potassium permanganate were obtained from R\&M Chemicals (Systerm, Malaysia). The other materials - sulfuric acid, phosphoric acid, hydrogen peroxide, and ethanol - were purchased from Merck $\mathrm{KGaA}$ (Darmstadt, Germany). Unless otherwise specified, all the reagents and materials involved were used as received without further purification. Deionized water (resistivity $\geq 18 \mathrm{M} \Omega$ ) was used during the experimental process.

\section{Synthesis of GO}

GO was synthesized via the simplified Hummers method in which a 9:1 sulfuric acid:phosphoric acid $(360: 40 \mathrm{~mL})$ solution was prepared, into which $3 \mathrm{~g}$ of graphite was added. ${ }^{51,52}$ Potassium permanganate ( $18 \mathrm{~g}$ ) was gradually added and the solution was left to oxidize for 3 days whilst being continuously stirred. After 3 days, the resulting solution was cooled to room temperature and poured onto ice $(\sim 400 \mathrm{~mL})$ along with $27 \mathrm{~mL}$ of $30 \%$ hydrogen peroxide. The solution was centrifuged (CR21GIII;Hitachi, Japan) and washed three times with $1 \mathrm{M}$ hydrogen chloride and six times with water. The final solution, the GO dispersion, was light brown in color. 


\section{Synthesis of $\mathrm{RGO} / \mathrm{TiO}_{2}$}

Titanium isopropoxide $(3.72 \mathrm{~mL})$ was added into $3.32 \mathrm{~mL}$ of TEA in a $25 \mathrm{~mL}$ volumetric flask (Favorit, PLT Scientific Sdn. Bhd) producing a titanium(IV) ionic $\left(\mathrm{Ti}^{4+}\right)$ solution with a concentration of $0.50 \mathrm{M}$. In order to form the $\mathrm{GO} / \mathrm{TiO}_{2}$ solution, $10 \mathrm{~mL}$ of $1 \mathrm{mg} / \mathrm{mL}$ of $\mathrm{GO}$ solution was added into a water:ethanol mixture $(1: 14) \mathrm{mL}$ with continuous stirring. After that, $3 \mathrm{~mL}$ of $\mathrm{Ti}^{4+}$ solution was added and the mixture stirred for 24 hours at room temperature to obtain a homogeneous suspension. The mixture was placed in a custom made Teflonlined autoclave and heated to $120^{\circ} \mathrm{C}$ for 24 hours. Two other samples were prepared by an identical procedure except for the final autoclave reaction temperature $\left(150^{\circ} \mathrm{C}\right.$ and $\left.180^{\circ} \mathrm{C}\right)$. The samples were labeled as $120 \mathrm{RGO} / \mathrm{TiO}_{2}, 150 \mathrm{RGO} / \mathrm{TiO}_{2}$, and $180 \mathrm{RGO} / \mathrm{TiO}_{2}$, with the number signifying the reaction temperature. The black precipitates were washed three times with ethanol, centrifuged at 13,000 $\mathrm{g}$ for 10 minutes, and dried at $60^{\circ} \mathrm{C}$. Pure $\mathrm{TiO}_{2}$ samples were also prepared using the same procedure; these samples are denoted as $120 \mathrm{TiO}_{2}, 150 \mathrm{TiO}_{2}$, and $180 \mathrm{TiO}_{2}$. RGO was also synthesized in the absence of titanium isopropoxide under the same conditions at $180^{\circ} \mathrm{C}$.

\section{Characterization}

The atomic structure of the samples was investigated by X-ray diffraction (XRD, D5000, Siemen) (XRD) using copper K $\alpha$ radiation $(\lambda=1.5418 \AA)$ at a scan rate of 0.02 degrees $\mathrm{s}^{-1}$. This was complemented by transmission electron microscopy (CM12; Philips) operated at $100 \mathrm{kV}$, which allowed an image of the nanoparticles and graphene flakes to be acquired. The chemical stability was investigated using thermogravimetric analysis (TGA) (Q500; TA Instruments, New Castle, DE) and the bond structure investigated using UV-visible spectroscopy with a scan rate of $240 \mathrm{~nm} / \mathrm{mm}$ (Evolution 300; Thermo Fisher Scientific, Pittsburgh, PA). The electrochemical performance was assessed using three-electrode cyclic voltammetry with a silver/silver chloride $3 \mathrm{M}$ sodium chloride reference electrode and a platinum counter electrode (CV-50W voltammetric analyzer; Bioanalytical Systems Inc, West Lafayette, IN).

\section{Electrochemical performance}

The working electrode was $3 \mathrm{~mm}$ in diameter and made from a glassy carbon electrode (GCE). Before modification, the bare GCE was polished with alumina slurry on microcloth pads (MetaServ 250, Buehler) and thoroughly rinsed with distilled water between each polishing step. The final cleaning step was successive washes with distilled water and anhydrous alcohol. The modified electrode was made by tapping the bare GCE onto the sample ten times successively. ${ }^{53}$ The cell electrolyte was formed by mixing $10 \mathrm{~mL}$ of $0.1 \mathrm{M}$ of potassium chloride with $190 \mu \mathrm{L}$ of $1.0 \mathrm{mM}$ mercuric chloride analyte. Once all three electrodes were immersed into the supporting electrolyte solution, nitrogen gas was bubbled through the solution for 15 minutes to remove any dissolved oxygen before the voltammogram was recorded. The potential range was checked before any readings on the voltammogram were recorded. All the voltammetric experiments were referred at an ambient temperature of $25^{\circ} \mathrm{C} \pm 2^{\circ} \mathrm{C}$.

\section{Results and discussion}

UV-visible absorption spectroscopy measurements for $\mathrm{RGO} /$ $\mathrm{TiO}_{2}$ nanocomposites are shown in Figure 1 and indicate the degree of reduction in the increase of $\mathrm{GO}$ as the reaction temperature increased. For pure GO, there was a peak at about $227 \mathrm{~nm}$ and a shoulder at around $300 \mathrm{~nm}$. The peak at $227 \mathrm{~nm}$ is assigned to the pi to anti-pi $\left(\pi \rightarrow \pi^{*}\right)$ transition of the aromatic carbon-carbon bonds and the shoulder at $300 \mathrm{~nm}$ to the $\mathrm{n}$ to anti-pi $\left(\mathrm{n} \rightarrow \pi^{*}\right)$ transitions of the carbon $=$ oxygen bonds. ${ }^{54}$ The $120 \mathrm{RGO} / \mathrm{TiO}_{2}$ sample had a broad peak centered at $227 \mathrm{~nm}$ and a shoulder at approximately $300 \mathrm{~nm}$. There was no evidence of a peak at $256 \mathrm{~nm}$, which is a characteristic of graphene and is attributed to the aromatic carbon = carbon bonds. For the $150 \mathrm{RGO} / \mathrm{TiO}_{2}$ and $180 \mathrm{RGO} / \mathrm{TiO}_{2}$ samples, the peak at $227 \mathrm{~nm}$ right-shifted to $256 \mathrm{~nm}$. This represents the partial restoration of the pi-conjugation network of the sample as a result of the hydrothermal and chemical reduction process. All the $\mathrm{RGO} / \mathrm{TiO}_{2}$ nanocomposite samples showed typical absorption of $\mathrm{TiO}_{2}$ with an absorption edge of around

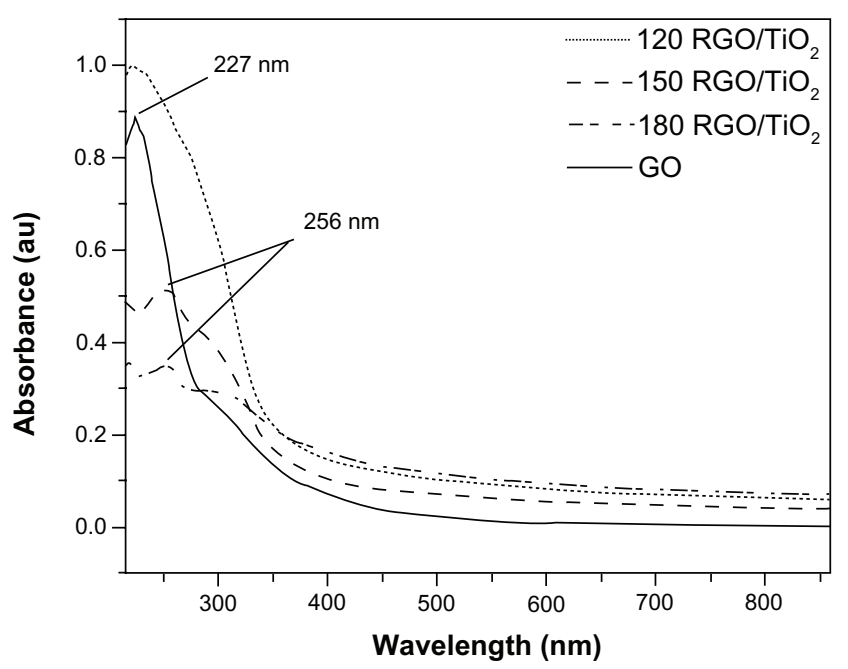

Figure I Ultraviolet-visible absorption spectra of reduced graphene oxide/titanium dioxide nanocomposites and graphene oxide.

Note: 120, 150, and 180 indicate the reaction temperature.

Abbreviations: $\mathrm{GO}$, graphene oxide; $\mathrm{RGO} / \mathrm{TiO}_{2}$, reduced graphene oxide/titanium dioxide nanocomposite. 
$360 \mathrm{~nm}$, while the $180 \mathrm{RGO} / \mathrm{TiO}_{2}$ sample showed a higher absorption edge of around $375 \mathrm{~nm}$.

Figure $2 \mathrm{~A}$ and $\mathrm{B}$ show the XRD patterns of the graphite, $\mathrm{GO}, \mathrm{RGO}$, pure $\mathrm{TiO}_{2}$, and $\mathrm{RGO} / \mathrm{TiO}_{2}$ nanocomposites. The dominant diffraction peak centered at around eleven degrees in the XRD pattern of GO corresponded to reflection from the (002) plane, ${ }^{55,56}$ whilst for raw graphite this reflection occurred at around 26 degrees and was very intense. For the RGO samples, the (002) reflection peak was broad and was centered at around 25 degrees. The broad diffraction peak of RGO indicates poor ordering of the sheets along the stacking direction, which implies the sample was comprised mainly from single or only a few layers of RGO. ${ }^{57}$ The band at 43 degrees corresponded to the turbostratic band of disordered carbon materials. ${ }^{58}$ No diffraction peak attributable to reflections from graphite crystal planes was observed, which suggests the stacking of the RGO sheets remained disordered and were not stacked together to form a detectable graphite structure.
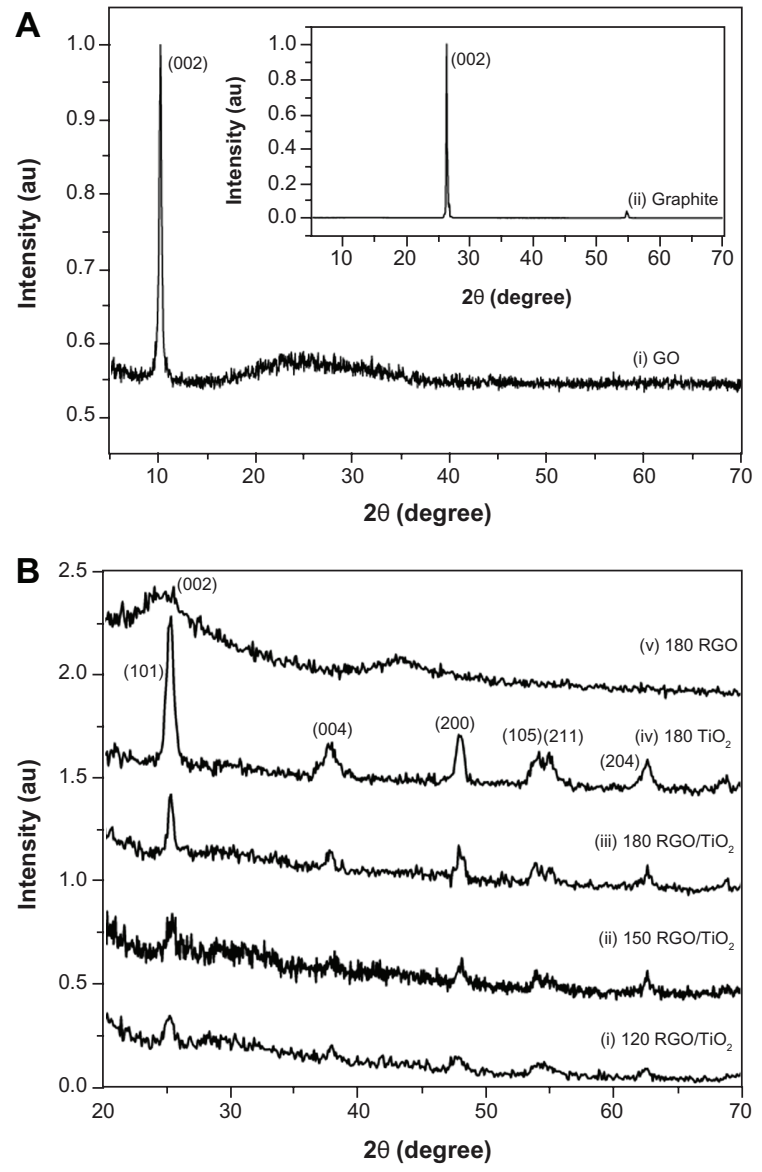

Figure 2 X-ray diffraction patterns of (A) graphite and graphene oxide and (B) reduced graphene oxide, titanium dioxide, and reduced graphene oxide/titanium dioxide nanocomposites.

Note: 120, 150, and 180 indicate the reaction temperature.

Abbreviations: GO, graphene oxide; RGO, reduced graphene oxide; $\mathrm{RGO} / \mathrm{TiO}_{2}$, reduced graphene oxide/titanium dioxide nanocomposite; $\mathrm{TiO}_{2}$, titanium dioxide.
In addition to the peaks attributable to carbon-based compounds, the XRD spectrum contained peaks which have been assigned to reflections from the anatase phase of tetragonal $\mathrm{TiO}_{2}$ with lattice constants of $\mathrm{a}=3.7892 \AA, \mathrm{b}=3.7892 \AA$, $c=9.5370 \AA$, and $\beta=90.0000$ (JCPDS 71-1167). The diffraction peaks can be indexed as reflections from the (101), (004), (200), (105), (211), and (204) planes, respectively. There was no evidence for the other phases of $\mathrm{TiO}_{2}$ being present. Comparing the $120 \mathrm{RGO} / \mathrm{TiO}_{2}$ and the $180 \mathrm{RGO} /$ $\mathrm{TiO}_{2}$ samples, there was an increase in peak intensities of the peaks attributed to the reflections from $\mathrm{TiO}_{2}$, which suggests the formation of larger $\mathrm{TiO}_{2}$ crystallites and enhancement of the $\mathrm{TiO}_{2}$ crystallization process. ${ }^{59}$ Full width at half maximum of the $\mathrm{TiO}_{2}$ (101) reflection for the $120 \mathrm{RGO} / \mathrm{TiO}_{2}, 150$ $\mathrm{RGO} / \mathrm{TiO}_{2}$, and $180 \mathrm{RGO} / \mathrm{TiO}_{2}$ samples was 1.1595 degrees, 0.9832 degrees, and 0.6378 degrees, respectively. Since the full width at half maximum is inversely proportional to the nanocrystal size (Scherrer equation), this result further confirms the hypothesis that higher hydrothermal temperatures produce greater $\mathrm{TiO}_{2}$ crystallization. The presence of graphene cannot be confirmed in the XRD spectra for the $\mathrm{RGO} / \mathrm{TiO}_{2}$ samples because there was no peak in the XRD spectrum that can be attributed to graphene. The most likely explanation is that the relatively weak and broad characteristic peak of graphene at 24.5 degrees was masked by the strong (101) $\mathrm{TiO}_{2}$ reflections at 25.4 degrees. ${ }^{60}$

Transmission electron micrographs of the samples are shown in Figure 3 along with the size distributions of the $\mathrm{TiO}_{2}$ nanoparticles. The nanoparticles were distributed uniformly on the basal plane of RGO nanosheets. The nanoparticles appeared to have a rounder shape in the $180 \mathrm{RGO} / \mathrm{TiO}_{2}$ sample when compared to the $120 \mathrm{RGO} / \mathrm{TiO}_{2}$ sample. The average size of the nanoparticles for the $120 \mathrm{RGO} / \mathrm{TiO}_{2}$, $150 \mathrm{RGO} / \mathrm{TiO}_{2}$, and $180 \mathrm{RGO} / \mathrm{TiO}_{2}$ was $20.4 \pm 3.9 \mathrm{~nm}$, $20.5 \pm 4.7 \mathrm{~nm}$, and $21.3 \pm 3.5 \mathrm{~nm}$, respectively. The histograms of the size distribution of the nanoparticles in the nanocomposites are exhibited on the right hand side of Figure 3. The size distribution of the $\mathrm{TiO}_{2}$ nanoparticles was narrower when the hydrothermal temperature increased. This trend agrees with the observation of more crystallized, round shaped, and homogeneous particles at $180^{\circ} \mathrm{C}$ compared to the less crystallized, amorphous, and heterogeneous particles at $120^{\circ} \mathrm{C}$. The role of TEA in the formation of the nanocrystals can be clearly seen in Figure 4 which shows a transmission electron micrograph of the $\mathrm{RGO} / \mathrm{TiO}_{2}$ sample synthesized under the same conditions at $180^{\circ} \mathrm{C}$ but without the presence of TEA. The $\mathrm{TiO}_{2}$ nanoparticles agglomerated and did not distribute homogenously on the RGO sheet. 

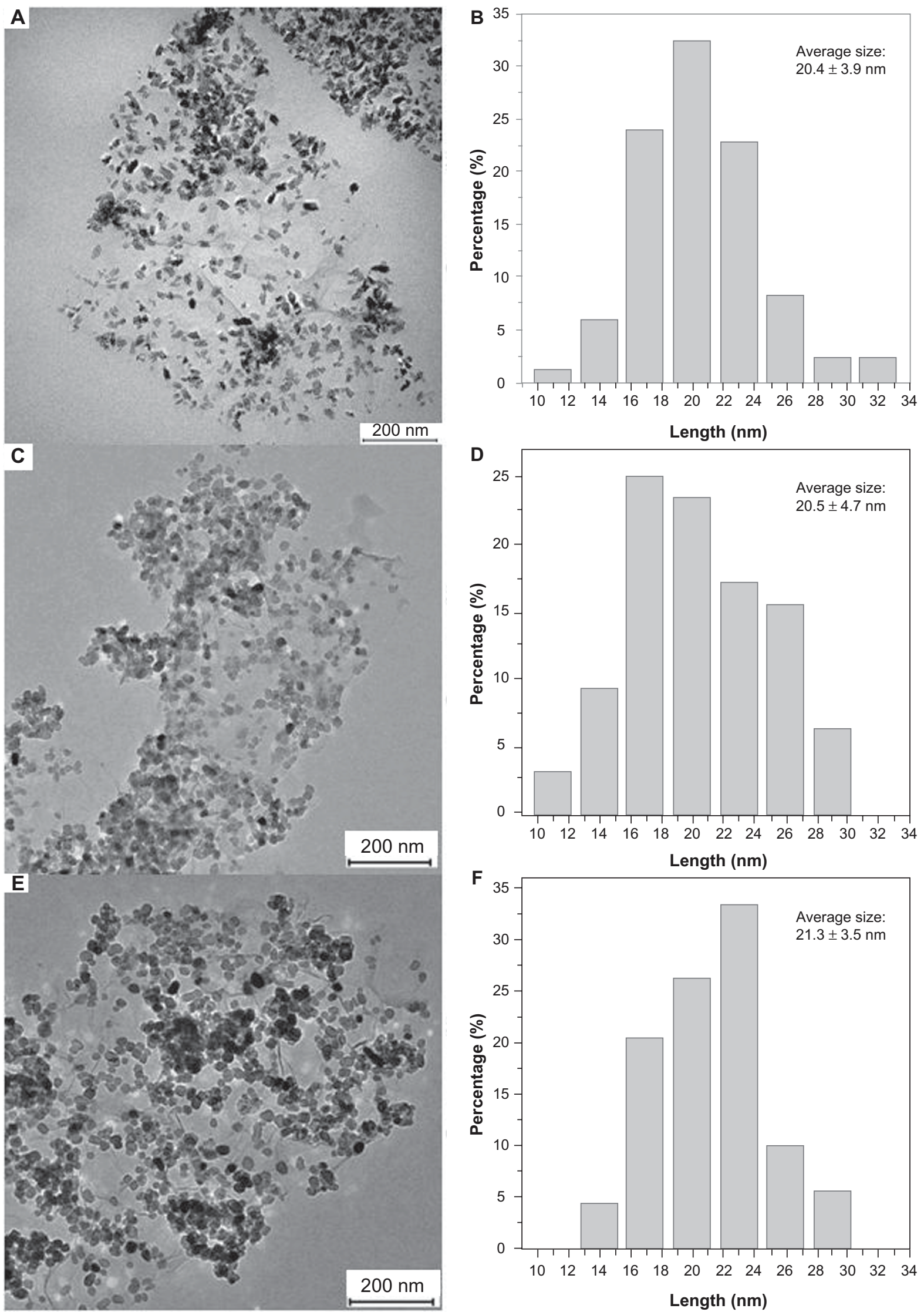

Figure $3(\mathbf{A}, \mathbf{C}$ and $\mathbf{E})$ Transmission electron micrograph and (B, D and $\mathbf{F})$ histogram of reduced graphene oxide/titanium oxide nanocomposites at $(\mathbf{A}$ and $\mathbf{B}) 120^{\circ} \mathrm{C}$, (C and D) $150^{\circ} \mathrm{C}$, and $(\mathbf{E}$ and $\mathbf{F}) 180^{\circ} \mathrm{C}$. 


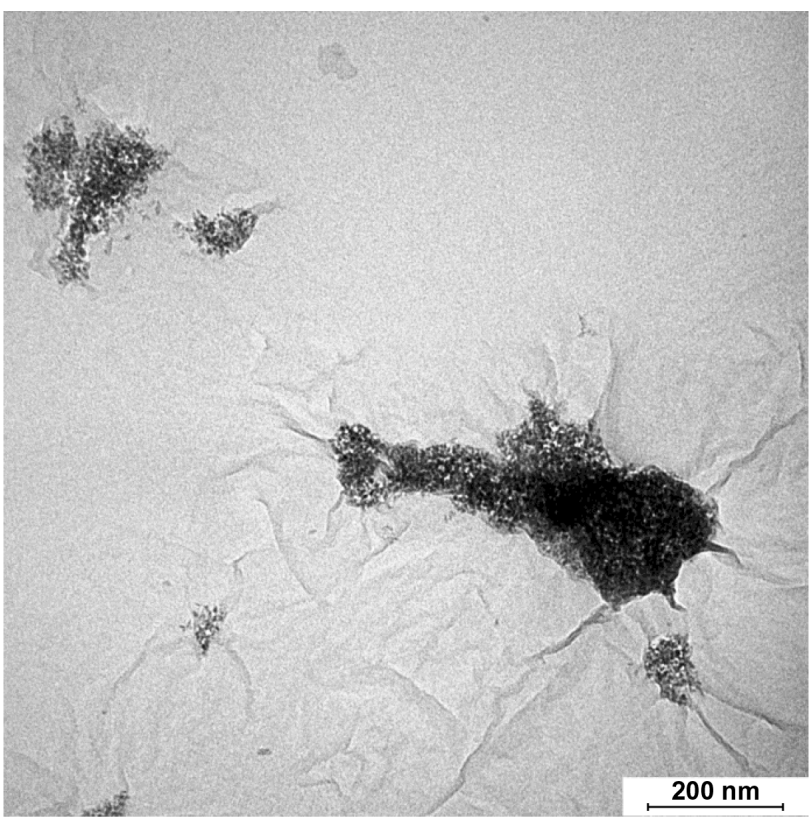

Figure 4 Transmission electron micrograph of reduced graphene oxide/titanium oxide nanocomposite synthesized without triethanolamine.

The successful decoration of $\mathrm{TiO}_{2}$ nanoparticles on $\mathrm{RGO}$ is also reflected in the TGA curves (Figure 5). The TGA curves for all the nanocomposites had four distinct regions (A, B, C, and D). In the region up to $100^{\circ} \mathrm{C}$ (region $\mathrm{A}$ ), the sample weight loss was caused by the resorption of physisorbed water. Between $150^{\circ} \mathrm{C}-300^{\circ} \mathrm{C}$ (region $\mathrm{B}$ ), the weight loss was a result of the decomposition of labile oxygen groups like carboxylate,

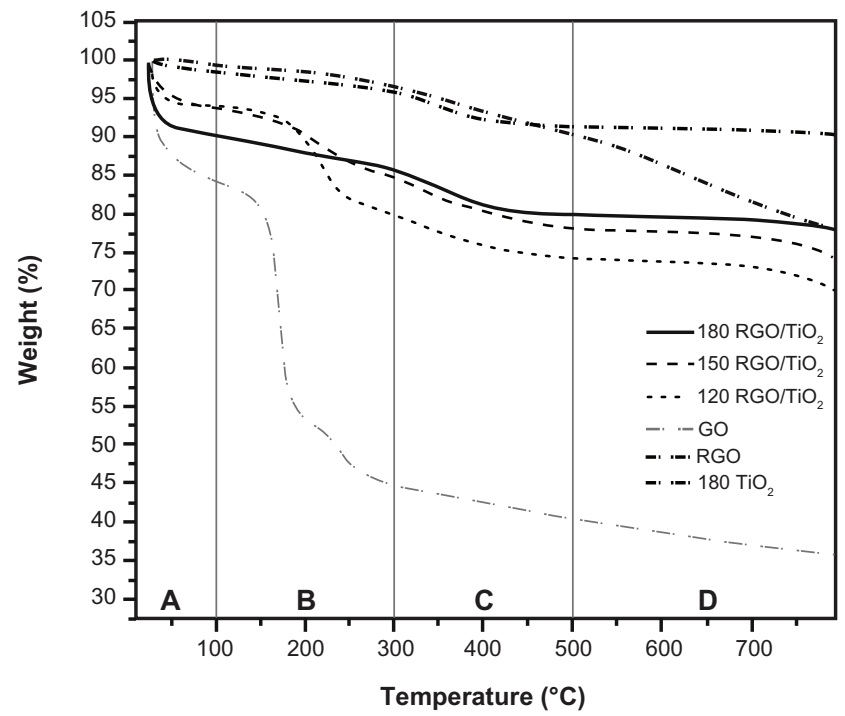

Figure 5 Thermogravimetric analysis curves of graphene oxide, reduced graphene oxide, titanium dioxide, and reduced graphene oxide/titanium dioxide nanocomposites.

Note: 120, 150, and 180 indicate the reaction temperature.

Abbreviations: GO, graphene oxide; RGO, reduced graphene oxide; $\mathrm{RGO} / \mathrm{TiO}_{2}$, reduced graphene oxide/titanium dioxide nanocomposite; $\mathrm{TiO}_{2}$, titanium dioxide. anhydride, or lactone groups. Region $\mathrm{C}$ occurred between $300^{\circ} \mathrm{C}-500^{\circ} \mathrm{C}$ and was associated with the removal of more stable oxygen groups such as phenol, carbonyl, and quinine. Above $500^{\circ} \mathrm{C}$ (region $\mathrm{D}$ ), high temperature pyrolysis of carbon skeleton occurred. ${ }^{50} \mathrm{GO}$ displayed a drastic weight loss $(40 \%$ of its original weight) in region $\mathrm{B}$ caused by the decomposition of labile oxygen-containing functional groups such as epoxy and hydroxyl groups. There was a similar loss of weight for the RGO, but the change was not so big. This result indicates that most of the GO oxygen-containing functional groups were reduced during the hydrothermal process, thereby increasing the thermal stability of the RGO. ${ }^{61}$ For the nanocomposites in region $\mathrm{B}$, the percentage of weight loss decreased with hydrothermal temperature. Specifically, the $120 \mathrm{RGO} / \mathrm{TiO}_{2}$, $150 \mathrm{RGO} / \mathrm{TiO}_{2}$, and $180 \mathrm{RGO} / \mathrm{TiO}_{2}$ samples lost $14.1 \%, 7.9 \%$, and $3.5 \%$ of their weight, respectively. This result indicates that the $180 \mathrm{RGO} / \mathrm{TiO}_{2}$ sample had the least amount of labile oxygen-containing functional groups attached to the surface. It also further indicates that a low hydrothermal temperature

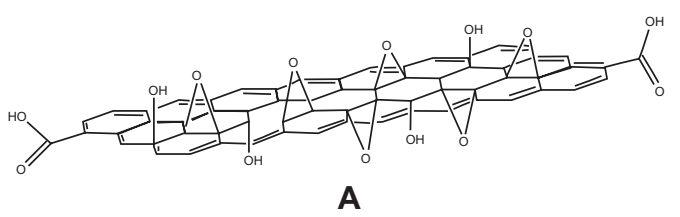

A
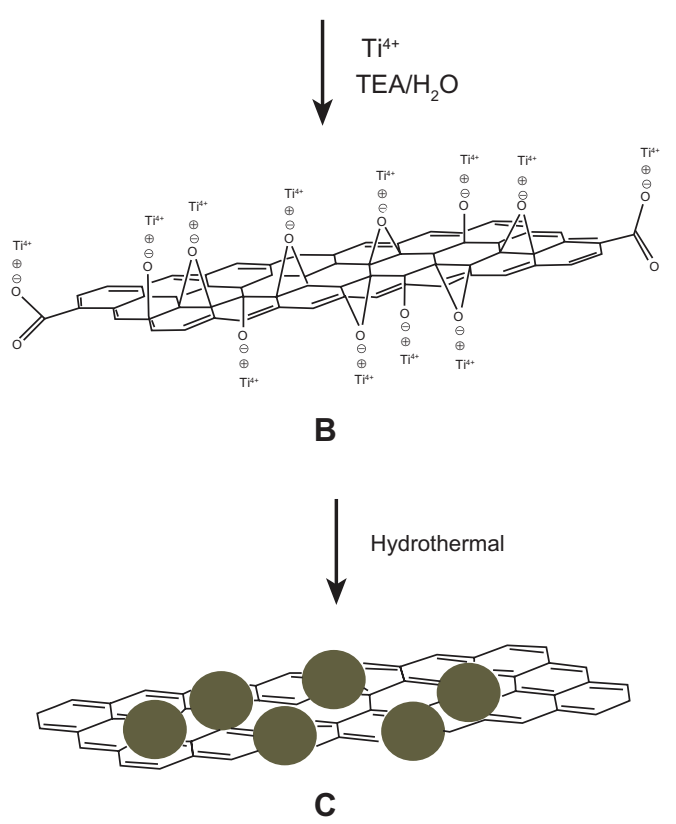

Figure 6 Schematic formation mechanism of the reduced graphene oxide/titanium dioxide nanocomposite. (A) Graphene oxide. (B) Electrostatic interaction between oxide functional groups of graphene oxide and titanium(IV) in the presence of triethanolamine. (C) Graphene decorated with titanium dioxide nanoparticles (filled circles) after hydrothermal treatment.

Abbreviations: $\mathrm{H}_{2} \mathrm{O}$, water; TEA, triethanolamine; $\mathrm{Ti}^{+}$, titanium(IV). 
$\left(120^{\circ} \mathrm{C}\right)$ was unable to reduce the oxygenous groups of GO in the nanocomposites efficiently.

A plausible schematic formation of $\mathrm{RGO} / \mathrm{TiO}_{2}$ is illustrated in Figure 6. GO was mixed with $\mathrm{Ti}^{4+}$ in the presence of TEA. This provided a platform for electrostatic interaction between the negatively-charged oxide functional groups of $\mathrm{GO}$ and the positively-charged $\mathrm{Ti}^{4+}$ (Figure 6B). Nucleation occurred at the sites, which resulted in the growth of $\mathrm{TiO}_{2}$ nanoparticles on the two-dimensional graphene nanosheets during the hydrothermal process (Figure 6C). The narrow size distribution of the $\mathrm{TiO}_{2}$ nanoparticles embedded on the graphene nanosheets may be due to the critical control of the TEA molecules. GO was reduced to graphene due to the simultaneous presence of $\mathrm{Ti}^{4+}, \mathrm{TEA}$, and hydrothermal treatment.

Figure 7 displays the electrochemical performance of the samples examined by cyclic voltammetry with a scan rate of $50 \mathrm{mV} \mathrm{s}^{-1}$. The background current behavior for bare GCE in potassium chloride supporting electrolyte with no mercury ions was almost flat and there were no oxidizing and reducing reactions (Figure 7A). On the other hand, the results for the bare GCE using the potassium chloride electrolyte containing mercury(II) ions $\left(\mathrm{Hg}^{2+}\right)$ in potassium chloride resulted in a distinctive oxidizing peak current observed between $+0.1 \mathrm{~V}$ and $+0.2 \mathrm{~V}$ (peak I; Figure 7B). The RGO-modified GCE in potas- sium chloride supporting electrolyte added with $\mathrm{Hg}^{2+}$ had an additional reductive peak between -0.2 and $+0.2 \mathrm{~V}$ (peak II; Figure $7 \mathrm{C}$ ). The entire hydrothermally prepared $\mathrm{RGO} / \mathrm{TiO}_{2}-$ modified GCE had improved electrochemical performance, signifying an increase in sensitivity to the detection of $\mathrm{Hg}^{2+}$ (Figure 7D-F).The $150 \mathrm{RGO} / \mathrm{TiO}_{2}$-modified GCE exhibited additional oxidization reactions between +0.4 and $+1.0 \mathrm{~V}$ (peak III) of all the samples. There were two distinct peaks. This oxidization reaction was in addition to the oxidative peak (peak I) seen in the RGO-modified GCE (Figure 7D). The sample also had a trough-like reductive peak (peak II), which shifted to a lower voltage by about $0.2 \mathrm{~V}$, and there was a reductive shoulder between +0.2 and $+0.8 \mathrm{~V}$ (peak IV). The $180 \mathrm{RGO} / \mathrm{TiO}_{2}$-modified GCE showed similar oxidative (peaks I and III) and reductive peaks (peaks II and IV; Figure 7E). For the $120 \mathrm{RGO} / \mathrm{TiO}_{2}$-modified GCE, the two reductive peaks (peak II - which shifted by about $0.2 \mathrm{~V}$ to the left - and peak IV) were enhanced by approximately $40 \mu \mathrm{A}$ (Figure 7F) when compared to the $180 \mathrm{RGO} / \mathrm{TiO}_{2}$-modified GCE. The peaks most likely arose through the stepwise reduction of $\mathrm{Hg}^{2+}+e^{-} \leftrightarrows \mathrm{Hg}^{+}$and $\mathrm{Hg}^{+}+\mathrm{e}^{-} \leftrightarrows \mathrm{Hg}^{0}$. The oxidative peak (peak II) that was so pronounced in the 150 $\mathrm{RGO} / \mathrm{TiO}_{2}$ - (Figure 7D) and $180 \mathrm{RGO} / \mathrm{TiO}_{2}$-modified GCE (Figure 7E) was missing in the $120 \mathrm{RGO} / \mathrm{TiO}_{2}$-modified
A

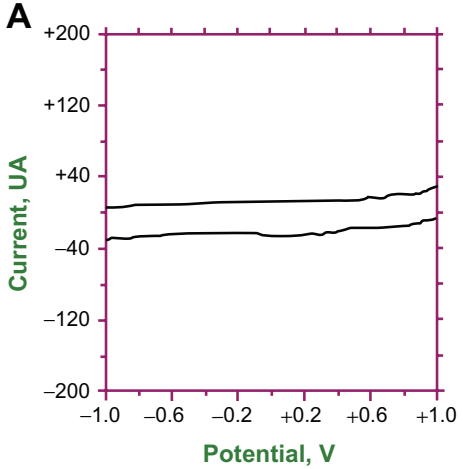

D

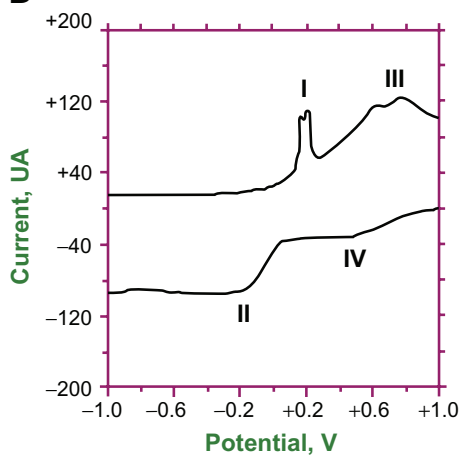

B

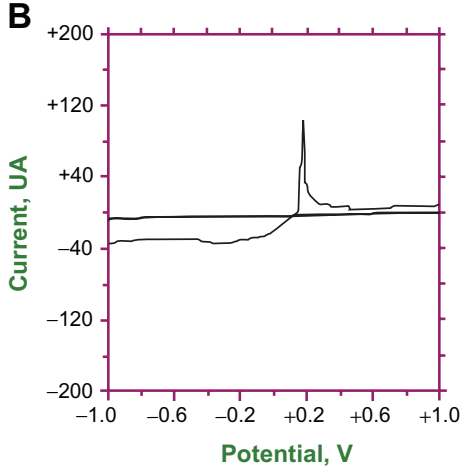

E

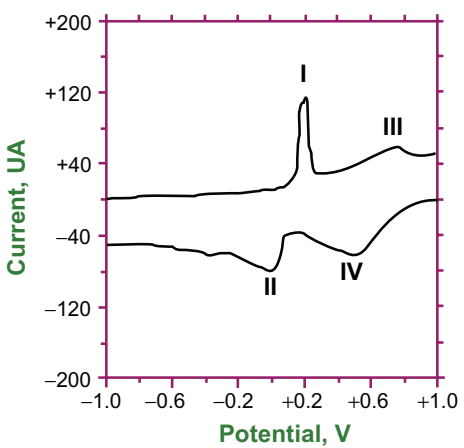

C

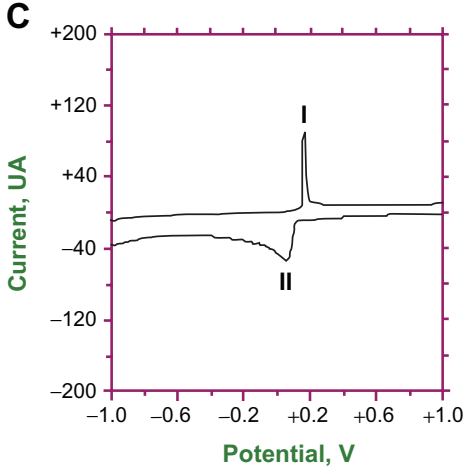

F

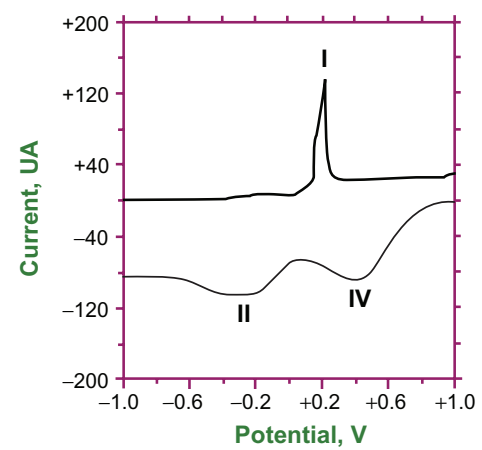

Figure 7 Electrochemical analysis of (A) bare glassy carbon electrode in potassium chloride supporting electrolyte, (B) bare glassy carbon electrode, (C) reduced graphene oxide-modified glassy carbon electrode, and reduced graphene oxide/titanium dioxide nanocomposite-modified glassy carbon electrode at $(\mathbf{D}) 150^{\circ} \mathrm{C},(\mathbf{E}) 180^{\circ} \mathrm{C}$, and (F) $120^{\circ} \mathrm{C}$ in potassium chloride supporting electrolyte and mercury(II) ionic solution. 
GCE. Among all the samples, the $120 \mathrm{RGO} / \mathrm{TiO}_{2}$-modified GCE possessed the best reducing reaction, which possibly makes it an efficient redox-recyclable material for the extraction of heavy element ions from wastewater.

\section{Conclusion}

$\mathrm{TiO}_{2}$ (with particle size of about $20 \mathrm{~nm}$ ) decorated RGO with high uniformity and were successfully synthesized via a simple hydrothermal process using TEA as the coreducing agent and capping agent. This simplified method has great advantage over other published methods of producing graphene-decorated $\mathrm{TiO}_{2}$ nanoparticles. The method allows control of the particle size distribution through alteration of the hydrothermal temperature. This enables the properties of the nanocomposite to be tailored to a specific application, as demonstrated by the detection of mercury ions in the electrochemical cell where the redox peaks in the cyclic voltammetric depended on the hydrothermal reactor temperature. This synthesis method can be easily extended to the fabrication of other classes of RGObased nanocomposites. The red-shift phenomenon in the UV analysis demonstrates the applicability of nanocomposites in photovoltaic and photocatalytic applications. The $\mathrm{RGO} / \mathrm{TiO}_{2}$ nanocomposites demonstrated enhanced electrochemical performance for the detection of $\mathrm{Hg}^{2+}$, suggesting the possibility of using them for detection of the heavy metal.

\section{Acknowledgments}

This work was financially supported by the High Impact Research Grant (UM.C/625/1/HIR/030) from the University of Malaya, the High Impact Research Grant (UM.C/625/1/ HIR/MOHE/05) from the Ministry of Higher Education Malaysia, University of Malaya Research Grant (RG09610AFR) and the Postgraduate Research Grant (UM.C/241/9) from the University of Malaya. BYS Chang would like to thank The Bright Sparks Unit of University of Malaya for the research incentives.

\section{Disclosure}

The authors report no conflicts of interest in this work.

\section{References}

1. Novoselov KS, Geim AK, Morozov SV, et al. Electric field effect in atomically thin carbon films. Science. 2004;306(5696):666-669.

2. Aleiner IL, Efetov KB. Effect of disorder on transport in graphene. Phys Rev Lett. 2006;97(23):236801-236804.

3. Meyer JC, Geim AK, Katsnelson MI, Novoselov MI, Booth TJ, Roth S. The structure of suspended graphene sheets. Nature. 2007; 446(7131):60-63.

4. Novoselov KS, Geim AK, Morozov SV, et al. Two-dimensional gas of massless Dirac fermions in graphene. Nature. 2005;438(7065): 197-200.
5. Schedin F, Geim AK, Morozov SV, et al. Detection of individual gas molecules adsorbed on graphene. Nat Mater. 2007;699:652-655.

6. Zhang Y, Tan YW, Stormer HL, Kim P. Experimental observation of the quantum Hall effect and Berry's phase in graphene. Nature. 2005;438(7065):201-204.

7. Ni ZH, Wang HM, Kasim J, et al. Graphene thickness determination using reflection and contrast spectroscopy. Nano Lett. 2007;7(9):2758-2763.

8. Sykes EC. Surface assembly: graphene goes undercover. Nat Chem. 2009;1(3):175-176.

9. Ishigami M, Chen JH, Cullen WG, Fuhrer MS, Williams ED. Atomic structure of graphene on $\mathrm{SiO}_{2}$. Nano Lett. 2007;7(6):1643-1648.

10. Balandin AA, Ghosh S, Bao W, Calizo I, Teweldebrhan D, Miao F, Lau CN. Superior Thermal Conductivity of Single-Layer Graphene. Nano Lett. 2008;8(3):902-907.

11. Konatham D, Striolo A. Molecular design of stable graphene nanosheets dispersions. Nano Lett. 2008;8(12):4630-4641.

12. Yoo E, Okata T, Akita T, Kohyama M, Nakamura J, Honma I. Enhanced electrocatalytic activity of $\mathrm{Pt}$ subnanoclusters on graphene nanosheet surface. Nano Lett. 2009;9(6):2255-2259.

13. Zhao J, Pei S, Ren W, Gao L, Cheng HM. Efficient preparation of large-area graphene oxide sheets for transparent conductive films. ACS Nano. 2010;4(9):5245-5252.

14. Zhu J. Graphene production: new solutions to a new problem. Nat Nanotechnol. 2008;3(9):528-529.

15. Kong BS, Geng J, Jung HT. Layer-by-layer assembly of graphene and gold nanoparticles by vacuum filtration and spontaneous reduction of gold ions. Chem Commun (Camb). 2009;16:2174-2176.

16. Scheuermann GM, Rumi L, Steurer P, Bannwarth W, Mulhaupt R. Palladium nanoparticles on graphite oxide and its functionalized graphene derivatives as highly active catalysts for the Suzuki-Miyaura coupling reaction. J Am Chem Soc. 2009;131(23):8262-8270.

17. Yuge R, Zhang M, Tomonari M, Yoshitake T, Iijima S, Yudasaka M. Site identification of carboxyl groups on graphene edges with Pt derivatives. ACS Nano. 2008;2(9):1865-1870.

18. Yang X, Zhang X, Ma Y, Huang Y, Wang Y, Chen Y. Superparamagnetic graphene oxide- $\mathrm{Fe}_{3} \mathrm{O}_{4}$ nanoparticles hybrid for controlled targeted drug carriers. J Mater Chem. 2009;19(18):2710-2714.

19. Lee S, Cho IS, Lee JH, et al. Two-step sol-gel method-based $\mathrm{TiO}_{2}$ nanoparticles with uniform morphology and size for efficient photoenergy conversion devices. Chem Mater. 2010;22(6):1958-1965.

20. Hong WS, Park JH, Han GY. Optimization of conditions for hydrogen production from anodized $\mathrm{TiO}_{2}$ nanotube-based photoelectrochemical cells. J Nanosci Nanotechnol. 2009;9(12):7293-7297.

21. Sato $\mathrm{S}$, White JM. Photodecomposition of water over $\mathrm{Pt} / \mathrm{TiO}_{2}$ catalysts. Chem Phys Lett. 1980;72(1):83-86.

22. Han CH, Hong DW, Han SD, Gwak J, Singh KC. Catalytic combustion type hydrogen gas sensor using $\mathrm{TiO}_{2}$ and UV-LED. Sens Actuators $B$ Chem. 2007;125(1):224-228.

23. Park JA, Moon J, Lee SJ, Kim SH, Zyung T, Chu HY. Structure and $\mathrm{CO}$ gas sensing properties of electrospun $\mathrm{TiO}_{2}$ nanofibers. Mater Lett. 2010;64(3):255-257.

24. Chen L, Tian J, Qiu H, et al. Preparation of $\mathrm{TiO}_{2}$ nanofilm via sol-gel process and its photocatalytic activity for degradation of methyl orange. Ceram Int. 2009;35(8):3275-3280.

25. Yazawa T, Machida F, Kubo N, Jin T. Photocatalytic activity of transparent porous glass supported $\mathrm{TiO}_{2}$. Ceram Int. 2009;35(8):3321-3325.

26. Dhas V, Muduli S, Agarkar S, et al. Enhanced DSSC performance with high surface area thin anatase $\mathrm{TiO}_{2}$ nanoleaves. Solar Energy. 2011;85(6):1213-1219.

27. Rahman M, Tajabadi F, Shooshtari L, Taghavinia N. Nanoparticulate hollow $\mathrm{TiO}_{2}$ fibers as light scatterers in dye-sensitized solar cells: layerby-layer self-assembly parameters and mechanism. Chemphyschem. 2011;12(5):966-973.

28. Sikong L, Kongreong B, Kantachote D, Sutthisripok W. Photocatalytic activity and antibacterial behavior of $\mathrm{Fe}^{3+}$-doped $\mathrm{TiO}_{2} / \mathrm{SnO}_{2}$ nanoparticles. Energy Res J. 2010;1(2):120-125. 
29. Huang Z, Maness PC, Blake DM, Wolfrum EJ, Smolinski SL, Jacoby WA. Bactericidal mode of titanium dioxide photocatalysis. J Photochem Photobiol A Chem. 2000;130(2-3):163-170.

30. Gerrity D, Ryu H, Crittenden J, Abbaszadegan M. Photocatalytic inactivation of viruses using titanium dioxide nanoparticles and lowpressure UV light. J Environ Sci Health A Tox Hazard Subst Environ Eng. 2008;43(11):1261-1270.

31. Mitoraj D, Janczyk A, Strus M, et al. Visible light inactivation of bacteria and fungi by modified titanium dioxide. Photochem Photobiol Sci. 2007;6(6):642-648.

32. Zhang AP, Sun YP. Photocatalytic killing effect of $\mathrm{TiO}_{2}$ nanoparticles on Ls-174-t human carcinoma cells. World $J$ Gastroenterol. 2004;10(21):3191-3193.

33. Srinivasan C, Somasundaram N. Bactericidal and detoxification effects of irradiated semiconductor catalyst, $\mathrm{TiO}_{2}$. Curr Sci. 2003;85(10): 1431-1438.

34. Desai VS, Kowshik M. Antimicrobial activity of titanium dioxide nanoparticles synthesized by sol-gel technique. Res J Microbiol. 2009; 4(3):97-103.

35. Acosta-Torres LS, Lopez-Marin LM, Nunez-Anita RE, Hernandez-Padron G, Castano VM. Biocompatible metal-oxide nanoparticles: nanotechnology improvement of conventional prosthetic acrylic resins. J Nanomater. 2011;2011:941561.

36. Li Q, Mahendra S, Lyon DY, et al. Antimicrobial nanomaterials for water disinfection and microbial control: potential applications and implications. Water Res. 2008;42(18):4591-4602.

37. Trapalis $\mathrm{C} . \mathrm{TiO}_{2}\left(\mathrm{Fe}^{3+}\right)$ nanostructured thin films with antibacterial properties. Thin Solid Films. 2003;433(1-2):186-190.

38. Shen J, Hu Y, Shi M, Li N, Ma H, Ye M. One step synthesis of graphene oxide-magnetic nanoparticle composite. J Phys Chem C. 2010;114(3):1498-1503.

39. Paek SM, Yoo E, Honma I. Enhanced cyclic performance and lithium storage capacity of $\mathrm{SnO}_{2}$ /graphene nanoporous electrodes with threedimensionally delaminated flexible structure. Nano Lett. 2009;9(1): $72-75$.

40. Meng X, Geng D, Liu J, Li R, Sun X. Controllable synthesis of graphene-based titanium dioxide nanocomposites by atomic layer deposition. Nanotechnology. 2011;22(16):165602.

41. Zhang $\mathrm{H}, \mathrm{Xu} \mathrm{P}, \mathrm{Du} \mathrm{G}$, et al. A facile one-step synthesis of $\mathrm{TiO}_{2} /$ graphene composites for photodegradation of methyl orange. Nano Res. 2011;4(3):274-283.

42. Lambert TN, Chavez CA, Hernandez-Sanchez B, et al. Synthesis and characterization of titania-graphene nanocomposites. J Phys Chem C. 2009;113(46):19812-19823.

43. Guo J, Zhu S, Chen Z, et al. Sonochemical synthesis of $\mathrm{TiO}_{2}$ nanoparticles on graphene for use as photocatalyst. Ultrason Sonochem. 2011;18(5):1082-1090.

44. Williams G, Seger B, Kamat PV. TiO2-graphene nanocomposites. UV-assisted photocatalytic reduction of graphene oxide. ACS Nano. 2008;2(7):1487-1491.

45. Zhang H, Lv X, Li Y, Wang Y, Li J. P25-graphene composite as a high performance photocatalyst. ACS Nano. 2010;4(1):380-386.
46. Byrappa K, Yoshimura M. Handbook of Hydrothermal Technology: A Technology for Crystal Growth and Materials Processing. New York: William Andrew Publishing; 2001.

47. Su C, Tseng CM, Chen LF, You BH, Hsu BC, Chen SS. Solhydrothermal preparation and photocatalysis of titanium dioxide. Thin Solid Films. 2006;498(1-2):259-265.

48. Demazeau G. Solvothermal processes: a route to the stabilization of new materials. J Mater Chem. 1999;9(1):15-18.

49. Kolen'ko YV, Maximov VD, Garshev AV, Meskin PE, Oleynikov NN, Churagulov BR. Hydrothermal synthesis of nanocrystalline and mesoporous titania from aqueous complex titanyl oxalate acid solutions. Chem Phys Lett. 2004;388(4-6):411-415.

50. Shen J, Yan B, Shi M, Ma H, Li N, Ye M. One step hydrothermal synthesis of $\mathrm{TiO}_{2}$-reduced graphene oxide sheets. J Mater Chem. 2011;21(10):3415-3421.

51. Huang NM, Lim HN, Chia CH, Yarmo MA, Muhamad MR. Simple room-temperature preparation of high-yield large-area graphene oxide. International Journal of Nanomedicine. 2011;6:3443-3448.

52. Lim HN, Huang NM, Lim SS, Harrison I, Chia CH. Fabrication and characterization of graphene hydrogel via hydrothermal approach as a scaffold for preliminary study of cell growth. Int $J$ Nanomedicine. 2011;6(1):1817-1823.

53. Bond AM, Marken F. Mechanistic aspects of the electron and ion transport processes across the electrode/solid/solvent (electrolyte) interface of microcrystalline decamethylferrocene attached mechanically to a graphite electrode. J Electroanal Chem. 1994;372(1-2):125-135.

54. Paredes JI, Villar-Rodil S, Martinez-Alonso A, Tascon JM. Graphene oxide dispersions in organic solvents. Langmuir. 2008; 24(19):10560-10564.

55. McAllister MJ, Li JL, Adamson DH, et al. Single sheet functionalized graphene by oxidation and thermal expansion of graphite. Chem Mater. 2007;19(18):4396-4404.

56. Zhang L, Li X, Huang Y, Ma YF, Wan XJ, Chen YS. Controlled synthesis of few-layered graphene sheets on a large scale using chemical exfoliation. Carbon. 2010;48(8):2367-2371.

57. Murugan AV, Muraliganth T, Manthiram A. Rapid, facile microwavesolvothermal synthesis of graphene nanosheets and their polyaniline nanocomposites for energy storage. Chem Mater. 2009; 21(21):5004-5006.

58. Xu ZW, Huang YD, Min CY, Chen L. Effect of $\gamma$-ray radiation on the polyacrylonitrile based carbon fibers. Radiat Phys Chem OxfEngl 1993. 2010;79(8):839-843.

59. Wang G. Hydrothermal synthesis and photocatalytic activity of nanocrystalline $\mathrm{TiO}_{2}$ powders in ethanol-water mixed solutions. $J \mathrm{Mol}$ Catal A Chem. 2007;274(1-2):185-191.

60. XuYJ, Zhuang Y, Fu X. New insight for enhanced photocatalytic activity of $\mathrm{TiO}_{2}$ by doping carbon nanotubes: a case study on degradation of benzene and methyl orange. J Phys Chem C. 2010;114(6): 2669-2676.

61. Shen J, Shi M, Yan B, Ma H, Li N, Ye M. Ionic liquid-assisted one-step hydrothermal synthesis of $\mathrm{TiO}_{2}$-reduced graphene oxide composites. Nano Res. 2011;4(8):795-806.
International Journal of Nanomedicine

\section{Publish your work in this journal}

The International Journal of Nanomedicine is an international, peerreviewed journal focusing on the application of nanotechnology in diagnostics, therapeutics, and drug delivery systems throughout the biomedical field. This journal is indexed on PubMed Central,

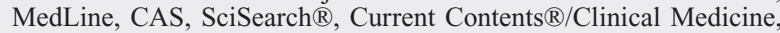

\section{Dovepress}

Journal Citation Reports/Science Edition, EMBase, Scopus and the Elsevier Bibliographic databases. The manuscript management system is completely online and includes a very quick and fair peer-review system, which is all easy to use. Visit http://www.dovepress.com/ testimonials.php to read real quotes from published authors. 